The concentrations of lecithin and free cholesterol in bile are more than double their respective concentrations in serum ${ }^{5}$. The secretion of such large amounts of lipid in bile suggests an important role for these substances in the digestive processes.

This investigation was supported in part by a research grant (H-2907) from the National Heart Institute, U.S. Public Health Service, and in part by a research grant from the American Heart Association.

Departments of Biochemistry and Medicine, Gerald B. Phillips College of Physicians and Surgeons, Columbia University and Presbyterian Hospital, New York, N.Y. (U.S.A.)

1 B. Isaksson, Acta Soc. Med. Upsaliensis, 56 (195I) I 77.

2 M. Polonovski, ANd R. Bourrillon, Bull. soc. chim. biol., 34 (I952) 712.

3 G. B. Phillips, Proc. Natl. Acad. Sci., U.S., 43 (I957) 566.

4 G. B. Phillips, Biochim. Biophys. Acta, 29 (1958) 594.

${ }^{5}$ G. B. Phillips, to be published.

${ }^{6}$ B. Isaksson, Acta Soc. Med. Upsaliensis, 59 (1954) 296.

Received February 2oth, I960

Biochim. Biophys. Acta, 41 (1960) 361-363

\title{
An improved method of isolation and determination of cordycepin
}

In I95 I CunNingham et al. ${ }^{1}$ isolated cordycepin from liquid cultures of the mold Cordyceps militaris (Linn.) Link. The work of BENTLEY et al..$^{2}$ showed cordycepin to be an adenine nucleoside containing a 3-deoxypentose with a branched carbon chain.<smiles></smiles>

Apparently a large part of the metabolism of this organism is directed to the production of this substance since 25 -100 $\mathrm{mg}$ of crystalline product can be isolated per liter of medium. This good yield of cordycepin offers the opportunity to study its biosynthesis, but a limitation to such studies is that the existing method of isolation requires some 20 days after harvesting.

This report describes an improved method of isolation of cordycepin, and in addition, it presents a colorimetric method for the quantitative estimation of cordycepose, the pentose moiety of the nucleoside.

Cordyceps militaris (Linn.) Link was obtained from Centraalbureau Voor Schimmelcultures, Baarn, Holland. The conditions for the production of cordycepin were essentially the same as those reported by Cunningham et al. ${ }^{1}$, who grew the 
mold in culture flasks containing $400 \mathrm{ml}$ of medium per flask. We have used $\mathrm{I} 8-1$ pyrex bottles containing 131 of medium each. The length of time required for the optimal production of the nucleoside was of the same order of magnitude reported for the smaller culture volumes ${ }^{1}$.

All slant cultures were maintained on oatmeal agar prepared as follows: $30 \mathrm{~g}$ of quick-cooking rolled oats and $600 \mathrm{ml}$ water were cooked for 30 to $45 \mathrm{~min}$ in a double boiler. This material was then strained through cheese cloth. $120 \mathrm{ml}$ of this extract were autoclaved for $30 \mathrm{~min}$ with $28 \mathrm{oml}$ water and $\mathrm{I} 2 \mathrm{~g}$ agar. (Io-ml portions of this were dispensed into test tubes, autoclaved, and slanted.) Cultures were transferred about every two weeks.

For the large-scale production of cordycepin a solution containing $65 \mathrm{~g}$ of enzymically prepared casein hydrolysate (Nutritional Biochemical Corporation) in Io $\mathrm{l}$ water was autoclaved in an I8-l pyrex bottle at a pressure of $\mathrm{I} 7 \mathrm{lb}$./in ${ }^{2}$. for $2 \mathrm{~h}$. A second solution containing I $30 \mathrm{~g}$ glucose in 31 water was autoclaved at the same time and added immediately afterward to the casein-hydrolysate solution. Slant cultures of Cordyceps, 2 to 4 weeks old, were shaken with Io $\mathrm{ml}$ of a sterile $0.9 \%$ saline solution. The resulting suspension of conidia was transferred to the 131 of cooled medium, a total of Io slants being used for the inoculum. The culture was allowed to grow at $23-25^{\circ}$ without shaking. Usually in 2 days sub-surface growth was visible, while in 3 days small surface colonies began to appear. By 7-Io days a wellformed pad had developed at the surface of the medium. The surface culture in this form was allowed to grow for 20-30 days. At intervals aliquot portions were removed under sterile conditions and suitable dilutions made for absorbancy readings at $260 \mathrm{~m} \mu$.

When the density at $260 \mathrm{~m} \mu$ reached a maximum, the mycelial pad was filtered off and the filtrate concentrated to approximately $0 . \mathrm{I}$ its original volume in a flash evaporator (Precision Scientific, Catalog No. 65486) at a temperature not exceeding $50^{\circ}$. Storage of the concentrate for I2 to $24 \mathrm{~h}$ at $4^{\circ}$ brought about the precipitation of a large quantity of material, which was removed by filtration. The filtrate was adjusted to $\mathrm{pH}$ II with $5 \mathrm{~N} \mathrm{NaOH}$ and passed through a column Io $\mathrm{cm}$ high $\times 7 \mathrm{I} \mathrm{cm}^{2}$ containing Dowex-I-chloride of 200-400 mesh and with a cross-linkage of 8. Most of the pigments produced by the browning reaction were adsorbed. Cordycepin was eluted by washing with $2-31$ water. The eluted material was concentrated in a rotary flash evaporator to a volume of $100 \mathrm{ml}$ and placed in the refrigerator at $4^{\circ}$ overnight. Cordycepin crystallized as dull matted needles, which were harvested by filtration and recrystallized from water. The yield of crystalline product from a I3-l batch of medium usually varied from I.o to I.5 g. Physical and chemical data obtained on this product were in agreement with that reported previously ${ }^{2}$.

\section{Colorimetric determination of cordycepose}

We observed that heating cordycepin with a slightly modified anthrone reagen $t^{3}$ resulted in the production of a cherry-red color and this was investigated further as a means of quantitatively estimating cordycepin. The reaction was negative with adenine. The reagent was prepared fresh daily by dissolving $0.2 \mathrm{~g}$ anthrone (Eastman Kodak Co.) in $100 \mathrm{ml} 90 \% \mathrm{H}_{2} \mathrm{SO}_{4}\left(\mathrm{I} 50 \mathrm{ml}\right.$ water plus $900 \mathrm{ml}$ conc. $\left.\mathrm{H}_{2} \mathrm{SO}_{4}\right) .5 .0 \mathrm{ml}$ of the anthrone reagent were added to I.oo-ml aliquot portions of solutions containing from I-I35 $\mu \mathrm{g}$ of cordycepin, mixed thoroughly and placed in an ice bath. A reagent blank was prepared using $1.00 \mathrm{ml}$ water in place of the cordycepin. All tubes were 
removed from the ice bath and heated in a water bath at $100^{\circ}$ for $10 \mathrm{~min}$. The tubes were then cooled and compared with the blank in a Klett photometer utilizing a No. 52 filter. The chromophore produced was found to be quite stable for several hours and obeyed the Beer-Lambert law between I and I35 $\mu \mathrm{g}$ of cordycepin. In the routine determination of cordycepose a standard of cordycepin whose concentration was previously determined from the extinction coefficient at $260 \mathrm{~m} \mu\left(\mathrm{I} 4.2 \cdot \mathrm{IO}^{3}\right.$ ) was run simultaneously with the blank and unknown. It was also found that the amount of color development in our procedure was the same whether the cordycepose was free or bound in the nucleoside. The absorption spectrum of the color produced in the anthrone determination of cordycepose is pictured in Fig. I, along with those obtained with glucose, adenosine, and deoxyadenosine under identical conditions.

Fig. I. Absorption spectra of pigments produced by the action of anthrone reagent on cordycepin, adenosine, deoxyadenosine, and glucose. $580 \mu \mathrm{g}$ of cordycepin, adenosine, and deoxyadenosine were analyzed by the anthrone method as described in the text. In the case of glucose, only roo $\mu \mathrm{g}$ was used. The absorption spectra recorded were read against a reagent blank in a Cary Recording Spectrophotometer.

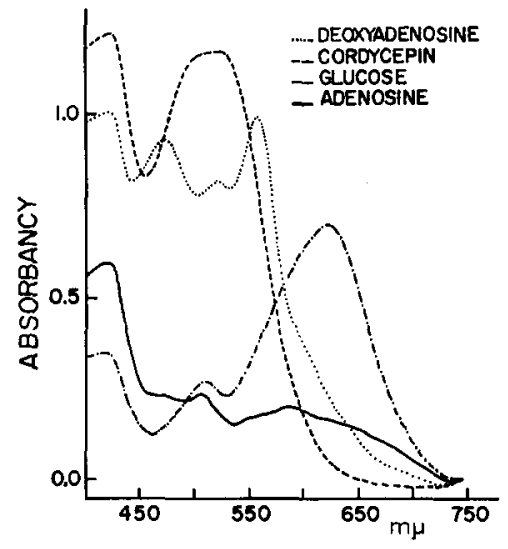

The anthrone method has proved most useful to us in our studies, because we produce our material in the presence of glucose and occasionally in the presence of adenosine.

We wish to acknowledge the technical assistance of Mrs. Martha DEWEy in this work. The first author is a Post-Sophomore Research Medical Student Fellow of the U.S. Public Health Service. This work was supported in part from grants from the National Science Foundation, NSF G-6423, and The American Cancer Society Institutional Research Grant 44-F.

Department of Biological Chemistry, The University of Michigan, Ann Arbor, Mich. (U.S.A.)

Nicholas M. KREDICH Armand J. Guarino

1 K. G. Cunningham, S. A. Hutchinson, W. Manson and F. S. Spring, J. Chem. Soc., (I95I) 2299.

2 H. R. Bentley, K. G. Cunningham and F. S. Spring, J. Chem. Soc., (I95I) 230 I.

3 D. L. MORrIs, Science, IO7 (1948) 254.

Received March 3rd, I960 